\title{
Reseña del libro Tutoría universitaria inclusiva. Guía de buenas prácticas
}

Tutoría Universitaria Inclusiva: guía de buenas prácticas para la Orientación de estudiantes con necesidades educativas específicas es un libro publicado en el año 2012 por la Editorial Narcea. Su foco principal son los estudiantes con discapacidad en el ámbito universitario español enmarcado en el modelo EEES -Espacio Europeo de Educación Superior-. Si bien este es su contexto, la fundamentación teórica y las orientaciones prácticas son pertinentes en el marco de nuestra Universidad, apegada al humanismo cristiano y a la calidad y pertenencia de su quehacer, lo cual constituye su principal aporte.

La atención a la diversidad en la Educación Superior dominicana ha sido un tema relegado. No se dispone de estadísticas a nivel nacional ni de un marco legal que la sustente y la oriente, como sucede en el sistema preuniversitario.

Asimismo, la tutoría universitaria, si bien está contemplada como responsabilidad del docente en el Reglamento de profesores y de carrera académica, en el Capítulo IV, Artículo 3.6 (PUCMM, 2011, p. 18), en sentido general, el cuerpo docente no parece ser totalmente consciente del potencial impacto de la misma en la formación de líderes, en cuanto propicia un seguimiento individual que previene situaciones de fracaso, angustia y abandono, a la vez que fortalece la formación en valores éticos, humanísticos y cristianos.

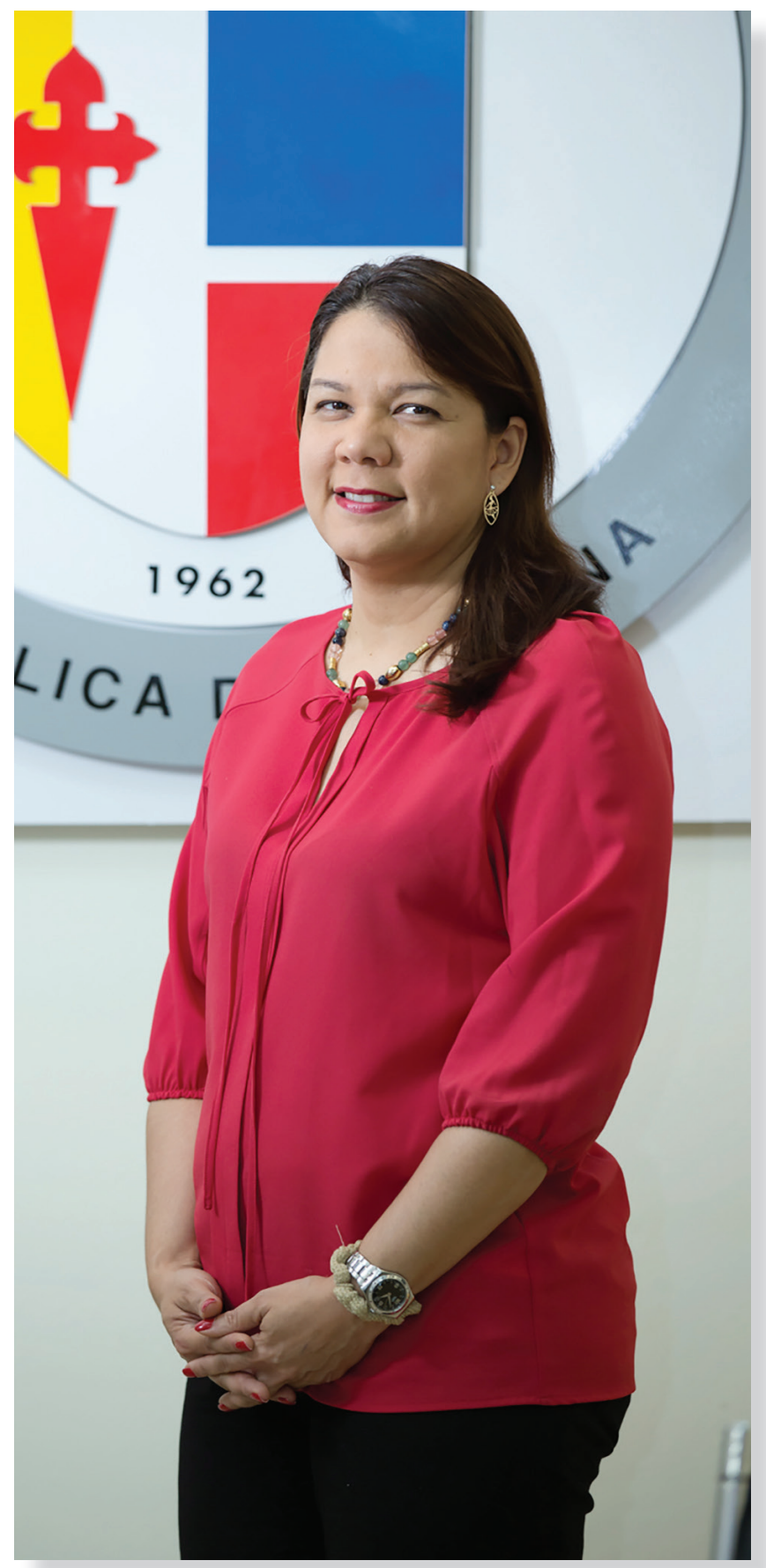

Cristina Amiama Espaillat

"Cristina Amiama Espaillat: Doctoranda en Ciencias de la Educación de la Universidad de Sevilla. Directora General de Educación Especial del MINERD. Coordinadora de la Especialidad en Educación Inclusiva para estudiantes con discapacidad y profesora del Departamento de Educación de la PUCMM. Para contactar a la autora: cm.amiama@ce.pucmm.edu.do 
Ambos temas, inclusión y tutoría universitarias, son abordados por Álvarez Pérez (2012) en el libro reseñado. Si bien es cierto que cada día ingresarán más estudiantes con discapacidad a la Educación Superior, producto de las medidas implementadas en el sistema preuniversitario, la inclusión no se centra solo en estudiantes con condición de discapacidad, sino que se abre a un conglomerado más amplio mediante la valoración de la diferencias personales, académicas, sociales, religiosas y culturales, requisito imprescindible para la atención a la diversidad que promueve nueva organización y espacios, siendo la tutoría la acción privilegiada.

\section{$13)^{\circ}$ \\ universitaria}

$$
8
$$

$\circ$

:IUTORIA

:TUTORIA

UNIVERSITARIA

INCLUSIVA

Guía de buenas

práculcas

para la orientación

de estudiantes

con necesidades

educativas especificas

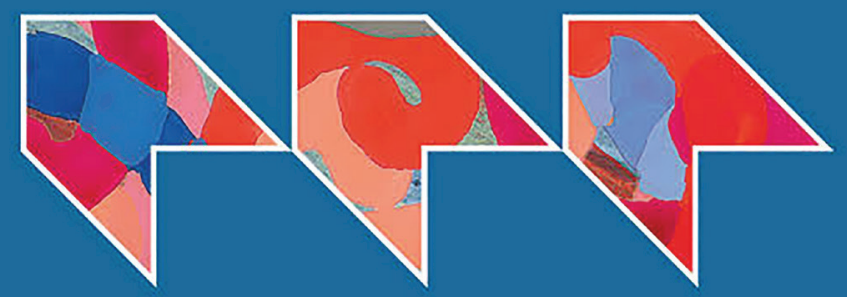

Pedro R. ÁLVAREZ PÉREZ (Coord.)

narcea
El autor se hace eco de las palabras de López y Zafra, 2003 "las medidas no deben ser sólo de tipo académico curricular, sino que también se deben implantar programas especializados que potencien el desarrollo de estos alumnos en el plano social, personal, académico y profesional" (p.15).

La tutoría con un enfoque en la atención a la diversidad es una señal de calidad educativa ya que promueve diferentes medidas, actuaciones y adaptaciones que permiten a todos los estudiantes alcanzar las metas educativas; además, contribuye a un enfoque integrador y humanista.

El libro se divide en dos partes: una fundamentación teórica, con 6 capítulos, y la guía de buenas prácticas, con dos capítulos. La fundamentación teórica está enmarcada en el modelo EEES que si bien parece alejado de la realidad dominicana, es válido en cuánto a su fundamentación teórica y modelo educativo.

El libro es fruto del trabajo que desarrolla la Universidad de Las Lagunas en torno a la orientación universitaria y su experiencia en programas de tutorías para distintos colectivos, además se fundamenta en una investigación sobre las principales barreras a que se enfrentan los estudiantes con discapacidad en el ámbito universitario y de las líneas estratégicas que dan respuesta a sus necesidades.

La obra aborda distintas dimensiones del proceso de 
integración de estudiantes con discapacidad en las aulas universitarias, desde una dimensión conceptual, diagnóstica, organizativa hasta la intervención.

Lo cual constituye su principal fortaleza, abordar la fundamentación teórica y presentar orientaciones precisas para la atención a la diversidad en el ámbito universitario, tema que ha sido relegado y poco estudiando.

El capítulo uno, Universidad y diversidad: la cultura de la igualdad como requisito, plantea los fundamentos para la atención de estudiantes con NEAE -necesidades específicas de apoyo educativo- en la Universidad como un reto que nos implica a todos y exige un cambio del centro de atención: del estudiante que no aprende y es el responsable de su fracaso, a los recursos y apoyos que se requieren para lograr las metas de educación de todos.

Mientras las aulas universitarias estaban pobladas de un grupo selecto de estudiantes, con enfoque y motivación clara, las clases magistrales y la "tutoría tradicional" funcionaban muy bien; pero hoy en día, los estudiantes son diversos en cuanto a sus capacidades, base cultural y motivación. Los profesores encuentran dificultades importantes para mantener el nivel, incluso algunos llegan a pensar que determinados estudiantes no deberían estar en las aulas universitarias (Biggs, 2005).

Se plantea que la enseñanza universitaria inclusiva debe contar con algunos elementos:

a. El planteamiento de la diversidad frente al etiquetado y la clasificación: la investigación realizada por Vislie en el año 2003, muestra que una vez que el alumno es etiquetado como diferente o "con dificultades" se cumple el efecto Pigmalión y todo lo que ocurre se le suele atribuir a sus dificultades.

b. La inclusión tiene que ver con el cambio de nuestros corazones y valores: se crea una comunidad de docentes que colaboran en la búsqueda de medidas creativas e innovadoras para lograr el aprendizaje de todos sus estudiantes.

c. Proporcionar respuestas educativas diferenciadas vs. respuestas unificadas: mientras más variados sean los materiales curriculares, los tipos de actividades y los recursos que se proponen a los estudiantes, mejor se garantiza el acceso a la información y el interés por los conocimientos planteados.

d. Tutoría y colaboración frente a la imposición: si se conciben las tutorías como acompañamiento en el aprendizaje y no como un mero formalismo de esperar que los estudiantes "vengan a...", sin dudas, conoceremos sus fortalezas y debilidades en los procesos de aprendizaje y esto permitirá una mejor planificación y desarrollo de estrategias de enseñanza. A la vez, si trabajamos en colaboración con otros docentes, propondremos mejores actuaciones que repercutirán en la calidad de los aprendizajes del alumnado.

e. La búsqueda de la excelencia docente frente al pasotismo acomodaticio del profesional: "Acometer una enseñanza universitaria inclusiva supone abordar procesos de cambio, movilizar, construir consensos, apoyar, transformar estructuras, contar con recursos y establecer alianzas con los involucrados" (p.35).

Los capítulos dos y tres abarcan el proceso de intervención psicopedagógica y las medidas para favorecer la transición, inclusión y desarrollo de los estudiantes con NEAE en la Universidad que se basan en dos principios: el principio de igualdad de oportunidades y el de equiparación de las oportunidades que establecen que todas las personas con independencia de su sexo, edad, origen racial, étnico, orientación sexual, creencias religiosas o discapacidad deben disfrutar de los mismos derechos fundamentales de los que disfrutan sus conciudadanos, de manera que puedan desarrollarse como personas y acceder a todos los recursos sociales, asegurando la igualdad de trato y una vida libre de discriminación.

El capítulo tres plantea en forma teórica medidas específicas para atender la diversidad que luego se concretizan en el capítulo 8, Guía de buenas prácticas para una orientación inclusiva.

Las principales medidas planteadas en ambos capítulos son:

- Aprobar normativas y reglamentos que establezcan y refuercen los principios de inclusión en el ámbito universitario.

- Acogida, información y asesoramiento a los estudiantes con discapacidad. 


\section{4 • NOTAS BIBLIOGRÁFICAS}

- Intervención, asistencia y provisión de recursos.

- Eliminación de barreras arquitectónicas y de comunicación. Desarrollo y difusión de investigaciones ligadas a la discapacidad.

- Formación a todo el personal con relación a las personas con discapacidad.

- Puesta en práctica de campaña de sensibilización y concientización.

- Establecimiento de relación con otras instituciones universitarias.

- Fomento de la colaboración entre docentes.

- Evaluación del servicio y de las acciones desarrolladas.

- Potenciar la creación de planes de tutoría.

- Disponer de personal especialista que apoye el proceso formativo centrado en la atención a la diversidad (profesores de lengua de señas, de Braille...).

- Crear espacios de diálogos.

Álvarez Pérez plantea que las primeras barreras que se deben eliminar son las arquitectónicas y las físicas, ya que generalmente las instalaciones son poco accesibles para estudiantes con discapacidad física.

El capítulo cuatro plantea la tutoría universitaria como "un servicio de calidad que permite cumplir con los objetivos encomendados a la Educación Superior en el Siglo XXI" (p.57) y como uno de los dos pilares en que se sustenta el modelo educativo propuesto por el EEES.

La tutoría se concibe como una estrategia de carácter transversal y la clasifican en varios tipos: de carrera o titulación, de materia o asignatura y aquellas dirigidas específicamente a estudiantes con discapacidad, objeto de este capítulo.

La palabra transversal implica que no es algo puntual que se ofrece para resolver un problema concreto en una asignatura, sino, más bien fomentar el desarrollo integral del estudiante desde el marco de la propia práctica educativa, y conformar el proceso madurativo del estudiante en todas sus dimensiones.

La tutoría debe centrarse en cinco aspectos claves de la enseñanza: los procesos de adaptación a la etapa universitaria, los procesos de aprendizaje, el asesoramiento acerca de las fuentes de información, los procesos de toma de decisiones y las relaciones con el entorno. En ese sentido, el tutor universitario cumple tres funciones básicas: informativa, asesora y supervisora del trabajo académico y orientadora.

Los capítulos quinto y sexto son más específicos para la atención de estudiantes con discapacidad en el contexto universitario español y en su desafío de adecuarse al Espacio Europeo de Educación Superior.

Los capítulos siete y ocho contienen sugerencias prácticas que todo docente debe estudiar y aplicar. Ambos tienen un enfoque eminentemente práctico y de fácil lectura, además de proveer todo lo necesario para desarrollar las actividades propuestas.

El capítulo siete, Desarrollo práctico de actividades de orientación al estudiante, está estructurado en cuatro áreas de intervención: transición y acceso a los estudios universitarios, integración y adaptación a los estudios universitarios, desarrollo de competencias académicas para el aprendizaje y desarrollo de competencias personales, sociales y profesionales.

Concluyo con palabras del autor: "...la Universidad tiene ante sí grandes retos que cumplir para elevar el nivel de calidad y las prestaciones, de modo que pueda hablarse de un verdadero modelo de educación inclusiva" (p. 149). Nosotros, los docentes, somos los principales actores de este proceso. Iniciemos con la valoración de las diferencias de nuestros estudiantes como un elemento enriquecedor. Fomentemos el trabajo colaborativo para diseñar estrategias y servicios de apoyo educativo que contemplen la atención individualizada para que todos puedan alcanzar las metas de su aprendizaje.

\section{Referencias}

Álvarez Pérez, P. (Coord.). (2012). Tutoría universitaria inclusiva: guía de buenas prácticas para la orientación de estudiantes con necesidades educativas específicas. Madrid. España: Narcea, S.A. De Ediciones.

Biggs, J. (2005). Calidad del aprendizaje universitario. Narcea, S. A. de Ediciones (Vol. 1). Madrid. doi:10.1017/CBO9781107415324.004

Pontíficia Universidad Católica Madre y Maestra (2011). Reglamento de profesores y de carrera académica PUCMM. 